\title{
Metallic conductivity versus charge disproportionation in c60complexes with noninteger average charges on fullerene
}

\section{$\operatorname{AUTHOR}(S)$ :}

Konarev, Dmitri V.; Khasanov, Salavat S.; Ishikawa, Manabu; Yudanova, Evgeniya I.; Shevchun, Artem F.; Mikhailov, Maksim S.; Stuzhin, Pavel A.; ... Yamochi, Hideki; Saito, Gunzi; Lyubovskaya, Ri ...

\section{CITATION:}

Konarev, Dmitri V....[et al]. Metallic conductivity versus charge disproportionation in C60complexes with noninteger average charges on fullerene. ChemistrySelect 2016, 1(2): 323-330

\section{ISSUE DATE:}

2016-02

URL:

http://hdl.handle.net/2433/229507

\section{RIGHT:}

This is the accepted version of the following article: [D. V. Konarev, S. S. Khasanov, M. Ishikawa, E. I. Yudanova, A. F. Shevchun, M. S. Mikhailov, P. A. Stuzhin, A. Otsuka, H. Yamochi, G. Saito, R. N. Lyubovskaya, ChemistrySelect 2016, 1, 323], which has been published in final form at https://doi.org/10.1002/slct.201500021. This article may be used for noncommercial purposes in accordance with Wiley Terms and Conditions for Self-Archiving.; The full-text file will be made open to the public on 3 February 2017 in accordance with publisher's 'Terms and Conditions for Self-Archiving'.; この論 文は出版社版でありません。引用の際には出版社版をご確認ご利用ください。; This is not the published version. Please cite only the published version. 


\title{
Metallic conductivity versus charge disproportionation in the $\mathbf{C}_{60}$ complexes with noninteger average charge on fullerene
}

\author{
Dmitri V. Konarev, ${ }^{*[a]}$ Salavat S. Khasanov, ${ }^{[b]}$ Manabu Ishikawa, ${ }^{[c]}$ Evgeniya I. Yudanova, ${ }^{[a]}$ Artem \\ F. Shevchun, ${ }^{[b]}$ Maksim S. Mikhailov, ${ }^{[d]}$ Pavel A. Stuzhin, ${ }^{[d]}$ Akihiro Otsuka, ${ }^{[c]}$ Hideki Yamochi, ${ }^{[c]}$ \\ Gunzi Saito, ${ }^{*[e, f]}$ and Rimma N. Lyubovskaya ${ }^{[a]}$
}

\begin{abstract}
:
Oxidation

$\left\{\right.$ cryptand $\left.\left(\mathrm{Na}^{+}\right)\right\}\left(\mathrm{C}_{60} 0^{-}\right)$

of

and

$\left\{\text { cryptand }\left(\mathrm{Na}^{+}\right)\right\}_{2}\left(\mathrm{C}_{60}{ }^{2-}\right)$ with integer -1 and -2 charges on fullerene by iron(II) octaethyltetrapyrazinoporphyrazine

allows crystallization of complexes with noninteger average charge on $\mathrm{C}_{60}$. $\left\{\right.$ Cryptand $\left.\left(\mathrm{Na}^{+}\right)\right\}\left(\mathrm{C}_{60}\right)_{3}-\cdot{ }^{-} \mathrm{C}_{6} \mathrm{H}_{4} \mathrm{Cl}_{2} \quad$ (1) with partial -0.33 charge on $\mathrm{C}_{60}$ has closely packed 3D structure formed by fragments of hexagonal fullerene layers. Complex 1 shows high conductivity of $50-60$ and $100-250 \mathrm{~S} \cdot \mathrm{cm}^{-1}$ in the 295$120 \mathrm{~K}$ range measured by four-probe and microwave techniques, respectively. Metallic behavior of $\mathbf{1}$ is observed down to $150-120 \mathrm{~K}$. It manifests a broad band in the IR range
\end{abstract}

with maximum at $2000 \mathrm{~cm}^{-1}$ attributed to the intraband transition in metal and a Dysonian EPR signal characteristic of highly conducting materials. Metallic conductivity is still observed in $\mathbf{1}$ after one month exposure to air. $\left\{\right.$ Cryptand $\left.\left(\mathrm{Na}^{+}\right)\right\}\left(\mathrm{C}_{60}\right)_{2}{ }^{-} \quad$ (2) and $\left\{\text { cryptand }\left(\mathrm{Na}^{+}\right)\right\}_{8}\left(\mathrm{C}_{60}\right)_{6} 6^{8-} \quad$ (3) with average -0.5 and -1.33 charges on $\mathrm{C}_{60}$ do not show metallic conductivity. This

Keywords: fullerene, complexes with partial charge transfer, metallic conductivity, charge disproportionation, crystal structure, IR and UV-visible-NIR spectra, magnetic properties can be explained by charge disproportionation and the formation of neutral and -1 charged $C_{60}$ in 2 due to their different cationic surrounding. Complex $\mathbf{3}$ has highly symmetric cationic surrounding for $\mathrm{C}_{60}$. Nevertheless, charge disproportionation also realized in 3 provides -1 and -2 charged $\mathrm{C}_{60}$. No dimerization of $\mathrm{C}_{60}$ is observed in $\mathbf{1}$ and $\mathbf{2}$ in spite of close packing of fullerenes in crystals. On the contrary, diamagnetic singly bonded $\left(\mathrm{C}_{60}{ }^{-}\right)_{2}$ dimers are formed in \{cryptand $\left.\left(\mathrm{Li}^{+}\right)\right\}_{2}\left(\mathrm{C}_{60}{ }^{-}\right)_{2} \cdot \mathrm{C}_{6} \mathrm{H}_{4} \mathrm{Cl}_{2} \cdot \mathrm{C}_{6} \mathrm{H}_{14}$ (4) with full -1 charge on fullerene as usually observed for the $\mathrm{C}_{60^{\circ-}}$ salts with close fullerene packing.

\section{Introduction}

Fullerenes can show promising conducting properties. ${ }^{[1-7]}$ Till now conducting fullerene compounds have been obtained mainly by fullerene doping with alkali, alkali-earth and lanthanide metals. ${ }^{[1-4]}$

[a] Dr. D.V. Konarev, Dr. E. I. Yudanova, Prof. R. N. Lyubovskaya Institute region, of Problems of Chemical Physics RAS, Chernogolovka, Moscow 142432 (Russia), E-mail: konarev@icp.ac.ru

[b] Dr. S.S. Khasanov, Dr. A.F. Shevchun Institute of Solid State Physics RAS, Chernogolovka, Moscow region, 142432 (Russia)

[c] Dr. A. Otsuka, Dr. M. Ishikawa, Prof. H. Yamochi Research Center for Low Temperature and Materials Sciences, Kyoto University, Sakyo-ku, Kyoto 606-8501 (Japan)

[d] Dr. M. S. Mikhailov, Prof. P. A. Stuzhin, Research Institute of Macroheterocycles, Ivanovo State University of Chemistry and Technology, Ivanovo, 153000 (Russia)

[e] Prof. Dr. Gunzi Saito

Faculty of Agriculture, Meijo University, 1-501 Shiogamaguchi, Tempaku-

ku, Nagoya 468-8502 (Japan), E-mail: gsaito@ccmfs.meijo-u.ac.jp

[f] Toyota Physical and Chemical Research Institute, 41-1, Yokomichi, Nagakute, Aichi 480-1192 (Japan)
The $\left(\mathrm{M}^{+}\right)\left(\mathrm{C}_{60^{-}}\right)$salts contain one-dimensional metallic polymers, ${ }^{[4]}$ while salts of the $\left(\mathrm{M}^{+}\right)_{3}\left(\mathrm{C}_{60}{ }^{3-}\right)(\mathrm{M}=\mathrm{K}, \mathrm{Rb}$ and $\mathrm{Cs})$ composition with three-dimensional (3D) packing of fullerenes are metals, which transmit to the superconducting state below $38 \mathrm{~K}$ under pressure and $33 \mathrm{~K}$ in ambient conditions. ${ }^{[1-3]}$ Being prepared by doping in gas phase these salts are generally obtained as powders. Conducting fullerene compounds can be obtained as crystals by direct growth from solution. Quasi-two-dimensional metallic conductivity is observed in the $\left(\mathrm{MDABCO}^{+}\right)\left(\mathrm{C}_{60^{\circ}}{ }^{-}\right) \cdot \mathrm{TPC}$ salt (where $\mathrm{MDABCO}^{+}$is $\mathrm{N}$-methyldiazabicyclooctanium cation, TPC is triptycene) containing closely packed hexagonal fullerene layers. ${ }^{[5,6]}$ In spite of layered structure, $\left(\mathrm{K}^{+}\right)(\mathrm{THF})_{5}\left(\mathrm{C}_{60} 0^{--}\right) \cdot 2 \mathrm{THF}$ shows one-dimensional electric conductivity. ${ }^{[7]}$ All these compounds manifest integer charge transfer (CT) to the fullerene molecule, namely, $-1,-2,-3$, etc.

In contrast to fullerenes, conducting compounds based on oxidized substituted tetrachalcogenofulvalenes ${ }^{[8]}$ and metal phthalocyanines $^{[9]}$ as well as reduced 7,7,8,8tetracyanoquinodimethanes ${ }^{[10]}$ and $\mathrm{M}(\mathrm{dmit})_{2}(\mathrm{M}=\mathrm{Ni}, \mathrm{Pd}, \mathrm{Pt}$, dmit is 1,3-dithiol-2-thione-4,5-dithiolate) ${ }^{[11]}$ have mainly partial and noninteger CT to donor or acceptor molecules (for example, charge transfer degree is $\delta=0.5$ or 0.67$)$. Combined with appropriate crystal structures, partial CT provides metallic conductivity by forming a partially filled conduction band. At full CT, Coulomb repulsion between electrons begins to play an important role to localize electrons and form insulating magnetic states. Therefore, 
compounds with partial CT to the fullerene molecule in conjunction with the presence of degenerated frontier molecular orbitals can be promising candidates to develop highly conducting systems. Though many ionic compounds based on fullerenes are known, only several compounds with partial and noninteger CT have been obtained. $\left(\mathrm{Na}^{+}\right)_{\mathrm{x}}(\mathrm{THF})_{\mathrm{y}} \mathrm{C}_{60}(\mathrm{x} \sim 0.4, \mathrm{y} \sim 2.2)^{[12]}$ shows conductivity of 50 $\mathrm{S} \cdot \mathrm{cm}^{-1}$ at room temperature (RT) and metallic behavior which can be explained by partial CT $(\delta \sim-0.4)$. The phase transition at $170 \mathrm{~K}$ results in the insulating state. Similar compounds were obtained with $\mathrm{K}^{+}$and $\mathrm{Li}^{+}$cations. ${ }^{[13]}$ The latter compound shows high conductivity (30 $\mathrm{S} \cdot \mathrm{cm}^{-1}$ at RT) but semiconducting behavior. Unfortunately, exact crystal structures of these compounds are unknown. Another fullerene complex with noninteger average charge on $\mathrm{C}_{60}$ is $\left\{\left(\mathrm{Ph}_{3} \mathrm{P}\right)_{3} \mathrm{Au}^{+}\right\}_{2}\left(\mathrm{C}_{60}\right)_{3}{ }^{2-} \cdot \mathrm{C}_{6} \mathrm{H}_{4} \mathrm{Cl}_{2}$. It contains corrugated hexagonal fullerene layers and has two $\left(\mathrm{Ph}_{3} \mathrm{P}\right)_{3} \mathrm{Au}^{+}$ cations per three $\mathrm{C}_{60}$ molecules. Average charge on $\mathrm{C}_{60}$ is -0.67 . Charges on the fullerene molecules were estimated to be -1 for two of $\mathrm{C}_{60}$ and close to zero for one of $\mathrm{C}_{60}$. Differently charged fullerenes have different cationic surroundings since positively charged gold atoms of $\left(\mathrm{Ph}_{3} \mathrm{P}\right)_{3} \mathrm{Au}^{+}$approach closer to $\mathrm{C}_{60} 0^{-}$. Charge disproportionation provides no metallic conductivity. ${ }^{[14]}$ Two other complexes with noninteger average charge on $\mathrm{C}_{60}$ are $\left\{\left(\mathrm{DMETEP}^{+}\right) \cdot \mathrm{Zn}^{\mathrm{II}} \mathrm{OEP}\right\}\left(\mathrm{C}_{60}\right)_{1.5} \cdot \mathrm{C}_{6} \mathrm{H}_{4} \mathrm{Cl}_{2} \quad(\mathrm{OEP}$ is octaethylporphyrin; DMETEP ${ }^{+}$is $N, N^{\prime}$-dimethyl- $N$-ethylthioethylpiperazinium cation) ${ }^{[15]}$ and $\left\{\mathrm{DB} 18 \mathrm{C} 6\left(\mathrm{~K}^{+}\right)\right\}_{4}\left(\mathrm{C}_{60}\right)_{5}{ }^{4-} \cdot 12 \mathrm{THF}$ (DB18C6 is dibenzo-18-crown-6-ether). ${ }^{[16]}$ Negatively charged and neutral fullerenes are spatially separated in these complexes, and charge disproportionation is also caused most probably by different cationic surroundings of $\mathrm{C}_{60}$.

In this work we report on the new general strategy developed for preparation of fullerene complexes with noninteger average CT to fullerene using iron(II) octaethyltetrapyrazinoporphyrazine (Fe $\left.{ }^{\mathrm{II}} \mathrm{TPyzPzEt} \mathrm{s}_{8}\right)$ as oxidizer for fullerene salts. Crystallization of $\left\{\right.$ cryptand $\left.\left(\mathrm{Na}^{+}\right)\right\}\left(\mathrm{C}_{60^{-}}{ }^{-}\right)$and $\left\{\text {cryptand }\left(\mathrm{Na}^{+}\right)\right\}_{2}\left(\mathrm{C}_{60} 0^{2-}\right)$ in the presence of $\mathrm{Fe}^{\mathrm{II}}$ TPyzPzEt 8 yields complexes: $\left\{\right.$ cryptand $\left.\left(\mathrm{Na}^{+}\right)\right\}\left(\mathrm{C}_{60}\right)_{3}^{-}$ $\cdot 2 \mathrm{C}_{6} \mathrm{H}_{4} \mathrm{Cl}_{2} \quad$ (1), $\quad\left\{\right.$ cryptand $\left.\left(\mathrm{Na}^{+}\right)\right\}\left(\mathrm{C}_{60}\right)_{2}{ }^{-} \quad$ (2) and \{cryptand $\left.\left(\mathrm{Na}^{+}\right)\right\}_{8}\left(\mathrm{C}_{60}\right)_{6}{ }^{8-}$ (3) with average $-0.33,-0.5$ and -1.33 charges on $\mathrm{C}_{60}$, respectively (cryptand is 4,7,13,16,21,24-hexaoxa1,10-diazabicyclo[8.8.8]hexacosane). Complex $\mathbf{1}$ is metal, whereas complexes $\mathbf{2}$ and $\mathbf{3}$ are non-metals and show charge disproportionation. Complexes $\mathbf{1}$ and $\mathbf{2}$ are air-stable and dimerization of fullerenes is not realized in them in spite of their close 3D packing. \{Cryptand $\left.\left(\mathrm{Li}^{+}\right)\right\}_{2}\left(\mathrm{C}_{60}{ }^{-}\right)_{2} \cdot \mathrm{C}_{6} \mathrm{H}_{4} \mathrm{Cl}_{2} \cdot \mathrm{C}_{6} \mathrm{H}_{14}$ (4) has full -1 charge on fullerene and in this case singly bonded $\left(\mathrm{C}_{60}{ }^{-}\right)_{2}$ dimers are formed. We present and discuss optical, magnetic and conducting properties of 1-4.

\section{Results and Discussion}

\section{Synthesis}

The choice of mild oxidizer is crucial for the synthesis of $\mathrm{C}_{60}$ complexes with noninteger average CT to fullerene. The first and second reduction potentials for $\mathrm{C}_{60}$ are -0.45 and $-0.82 \mathrm{~V}$ vs SCE in non-coordinating $o$-dichlorobenzene ${ }^{[17]}$. Therefore, negative reduction potential for appropriate oxidizer should be lower. In this work iron(II) octaethyltetrapyrazinoporphyrazine $\left(\mathrm{Fe}^{\mathrm{II}} \mathrm{TPyzPzEt} 8\right)$ was found to be suitable oxidizer for fullerene anions. The $1^{\text {st }}$ welldefined reduction wave observed for Fe ${ }^{\mathrm{II}} \mathrm{TPyzP}$ Et8 in coordinating DMSO at $-0.19 \mathrm{~V}$ (vs Ag/AgCl) (Figure S1) or $-0.235 \mathrm{~V}$ (vs SCE) can be assigned to the $\mathrm{Fe}^{\mathrm{II}} / \mathrm{Fe}^{\mathrm{I}}$ reduction couple with the formation of the $\left[\mathrm{Fe}^{\mathrm{I} T P y z P z E t}(2-)\right]^{-}$anion. As a result, $\mathrm{Fe}^{\mathrm{II}} \mathrm{TPy}_{\mathrm{TPzE}} \mathrm{t}_{8}$ shows stronger acceptor properties than $\mathrm{C}_{60}$ and can partially oxidize the $\left\{\right.$ cryptand $\left.\left(\mathrm{Na}^{+}\right)\right\}\left(\mathrm{C}_{60^{-}}\right)$or $\left\{\text {cryptand }\left(\mathrm{Na}^{+}\right)\right\}_{2}\left(\mathrm{C}_{60} 0^{2-}\right)$ salts whereas $\mathrm{Fe}^{\mathrm{II}}{ }^{\mathrm{TPy}} \mathrm{PPzt}_{8}$ is dissolved to form deep violet $\left\{\right.$ cryptand $\left.\left(\mathrm{Na}^{+}\right)\right\}\left\{\mathrm{Fe}^{\mathrm{I}} \mathrm{TPyzPzEt}_{8}(2-)\right\}^{-} \quad$ salt. Dissolution of stoichiometric amount of $\mathrm{Fe}^{\mathrm{II}} \mathrm{TPyzPzEt}_{8}$ together with $\left\{\right.$ cryptand $\left.\left(\mathrm{Na}^{+}\right)\right\}\left(\mathrm{C}_{60^{-}}\right)$followed by precipitation of crystals by hexane allow $\mathbf{1}$ and $\mathbf{2}$ to be crystallized together with the \{cryptand $\left.\left(\mathrm{Na}^{+}\right)\right\}\left(\mathrm{C}_{60^{-}}{ }^{-}\right) \cdot \mathrm{C}_{6} \mathrm{H}_{4} \mathrm{Cl}_{2}$ salt with full -1 charge on $\mathrm{C}_{60}$. Dissolution of stoichiometric amount of $\mathrm{Fe}^{\mathrm{II}} \mathrm{TPyzP} \mathrm{Et}{ }_{8}$ together with $\left\{\text { cryptand }\left(\mathrm{Na}^{+}\right)\right\}_{2}\left(\mathrm{C}_{60}{ }^{2-}\right)$ followed by precipitation of crystals by hexane allow the crystals of $\mathbf{3}$ to be obtained together with the crystals of $\left\{\right.$ cryptand $\left.\left(\mathrm{Na}^{+}\right)\right\}\left(\mathrm{C}_{60}{ }^{\circ-}\right) \cdot \mathrm{C}_{6} \mathrm{H}_{4} \mathrm{Cl}_{2} \quad$ and $\left\{\text { cryptand }\left(\mathrm{Na}^{+}\right)\right\}_{2}\left(\mathrm{C}_{60}{ }^{2-}\right)^{18}$. Single crystal samples of fullerene complexes obtained in both syntheses have been identified by X-ray diffraction. The crystal samples of different phases are separated easily due to their shape (crystal habit). All the measurements of optical, EPR spectra and conductivity of 1-3 were carried out on the single crystal samples, one or several ones, separated under microscope in accordance of their habit and tested by X-ray diffraction, i.e. well identified crystal samples. We also suppose that complexes with noninteger average CT to $\mathrm{C}_{60}$ could be obtained by adding corresponding amount of neutral $\mathrm{C}_{60}$ to the solutions of $\left\{\right.$ cryptand $\left.\left(\mathrm{Na}^{+}\right)\right\}\left(\mathrm{C}_{60} 0^{-}\right)$or $\left\{\text {cryptand }\left(\mathrm{Na}^{+}\right)\right\}_{2}\left(\mathrm{C}_{60} 0^{2-}\right)$. However, no crystals of the complexes with noninteger $\mathrm{CT}$ to $\mathrm{C}_{60}$ were obtained in this case.

\section{Crystal structure, optical, magnetic and conducting properties of $\left\{\right.$ cryptand $\left.\left(\mathrm{Na}^{+}\right)\right\}\left(\mathrm{C}_{60}\right)_{3}{ }^{-} \cdot 2 \mathrm{C}_{6} \mathrm{H}_{4} \mathrm{Cl}_{2}(1)$}

Crystal structure of $\mathbf{1}$ was determined from X-ray diffraction on a single crystal. In spite of slow cooling down to $90 \mathrm{~K}$, all components of the complex are strongly disordered (see Experimental part). We show only major orientation for the disordered parts in Fig. 1. There are three fullerenes per one cryptand $\left(\mathrm{Na}^{+}\right)$cation. Average charge on $\mathrm{C}_{60}$ is -0.33 , and $\mathbf{1}$ is a complex with noninteger $\mathrm{CT}$ to fullerene.

Complex 1 has close 3D packing of fullerenes penetrated by continuous channels occupied by the cryptand $\left(\mathrm{Na}^{+}\right)$cations and solvent $\mathrm{C}_{6} \mathrm{H}_{4} \mathrm{Cl}_{2}$ molecules located in the corners of each channel (Fig. 1a). The fragments of nearly ideal hexagonal fullerene layers are located in the plane approximately parallel to the diagonal to the $a c$ plane and the $b$ axis (Fig. 1b). These fragments have width of three fullerene rows since they are separated by the channels (Fig. 1b). As a result, fullerenes from the central row have six fullerene neighbors, and each $\mathrm{C}_{60}$ from the rows adjacent to the channels has only four fullerene neighbors. All interfullerene center-to-center (ctc) distances in these fragments are in the 9.85-9.95 $\AA$ range (Fig. 1b). Hexagonal fullerene fragments are also closely packed along the $c$ axis with the ctc interfullerene distance of only $9.95 \AA$ (Fig. 1a). All these distances are essentially shorter than the van der Waals (vdW) diameter of $\mathrm{C}_{60}$ of $10.18 \AA$ A. Potentially electron conductivity can be realized approximately along the plane parallel to the diagonal to the $a c$ plane and the $b$ axis. 
To discuss the possibility of charge disproportionation in $\mathbf{1}$ the conditions for electrostatic interaction between the cryptand $\left(\mathrm{Na}^{+}\right)$ cations and fullerenes should be considered. Each of three independent fullerenes in $\mathbf{1}$ is surrounded by three cations. The shortest distances between the centers of three independent $\mathrm{C}_{60}$ and the $\mathrm{Na}^{+}$ions are close $(8.12,8.16$ and $8.18 \AA$ ). Other cations have essentially longer distances between the centers of $\mathrm{C}_{60}$ and the $\mathrm{Na}^{+}$ ions which are also rather close for three independent $\mathrm{C}_{60}$ (10.05$10.32 \AA$ ). Therefore, conditions for electrostatic interactions of three independent fullerenes with the cations are similar and that can provide delocalization of negative charge over fullerenes.

Conductivity of $\mathbf{1}$ was measured by four-probe and microwave techniques on oriented single crystals from advanced crystal surface parallel to the crystallographic (101) plane (the plane coming along the $b$ axis and the diagonal to the $a c$ plane as shown in inset in Fig. 2a). High RT conductivity of the crystal of $55 \mathrm{~S} \cdot \mathrm{cm}^{-1}$ increases with the temperature decrease down to $220 \mathrm{~K}$ showing metallic behavior. Conductivity decreases slightly below this temperature and the abrupt decrease of conductivity is observed only below $120 \mathrm{~K}$ showing the transition to the semiconducting state ( $E_{\mathrm{a}}$ estimated at $T$ $<30 \mathrm{~K}$ is about $6 \mathrm{meV}$ ).

Microwave conductivity was also measured for oriented single crystal in the same plane. The frequency dependence of surface impedance calculated from microwave absorption in the $120<T<$ $200 \mathrm{~K}$ range corresponds to the normal skin effect in the compound with free carriers. Microwave conductivity of $100-240 \mathrm{~S} \cdot \mathrm{cm}^{-1}$ in the $120-200 \mathrm{~K}$ range (Fig. 2b) is higher than conductivity measured by four-probe technique and shows metallic behavior down to $120 \mathrm{~K}$. Transition to the nonmetallic state is observed below $120 \mathrm{~K}$ since absorption at $T=5 \mathrm{~K}$ and the frequency dependence of microwave absorption are absent in the $120-5 \mathrm{~K}$ range.

The UV-visible-NIR and IR spectra of $\mathbf{1}$ are shown in Fig. 3. Bands with the maxima at 346 and 1072 nm (Fig. 3a, arrows) were attributed to fullerenes. The latter band is generally ascribed to $\mathrm{C}_{60} 0^{-}$. A broad weak band at $667 \mathrm{~nm}$ (Fig. 3a, arrow) can most probably be attributed to CT between neutral fullerenes. It is known that the CT band associated with electron transfer between fullerenes is manifested in the spectrum of $\mathrm{C}_{60}$ at about $450 \mathrm{~nm}^{[19]}$. The lowest energy absorption band can be found even in the IR range with the maximum at about $2000 \mathrm{~cm}^{-1}$ (Fig. 3b). The origin of this band can be interpreted by either an intraband transition in metal or intermolecular CT from $\mathrm{D}^{0}$ (or $\mathrm{A}^{--}$) to $\mathrm{D}^{{ }^{+}}$(or $\mathrm{A}^{0}$ ) for the charge separated case. Only in a rare system with extremely small on-site Coulomb repulsion, a low-energy band appears from the CT process between $\mathrm{D}^{\bullet+}$ (or $\mathrm{A}^{\bullet-}$ ) ions. The energy of the CT process between cryptand $\left(\mathrm{Na}^{+}\right)$and $\mathrm{C}_{60}$ should be high whereas CT between $\mathrm{C}_{60}{ }^{\circ}$ is not observed at such low energies. Generally, bands associated with

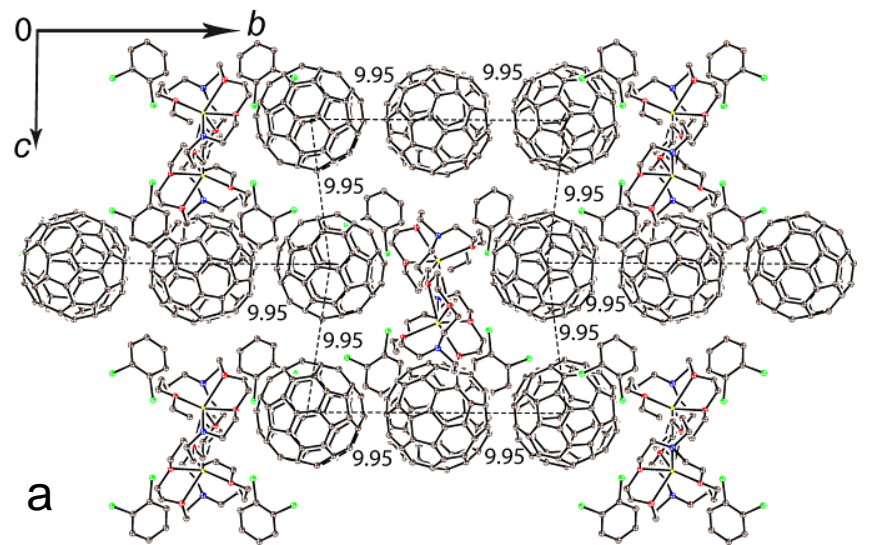

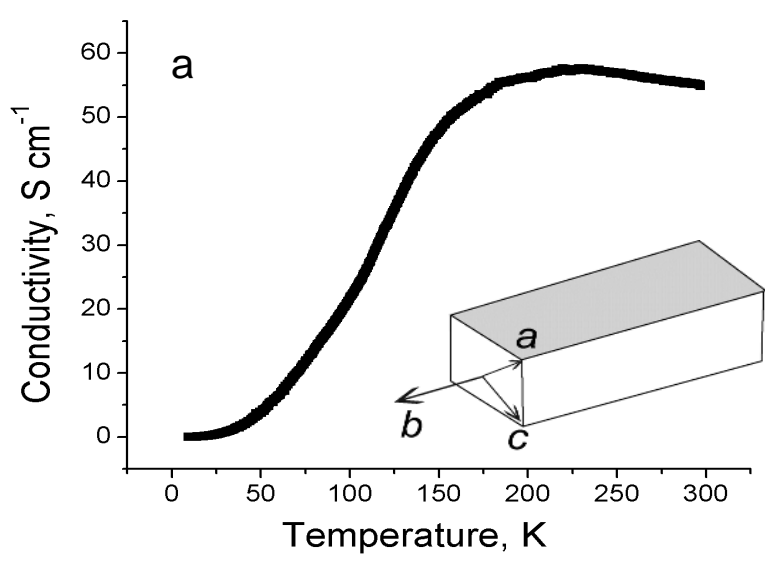

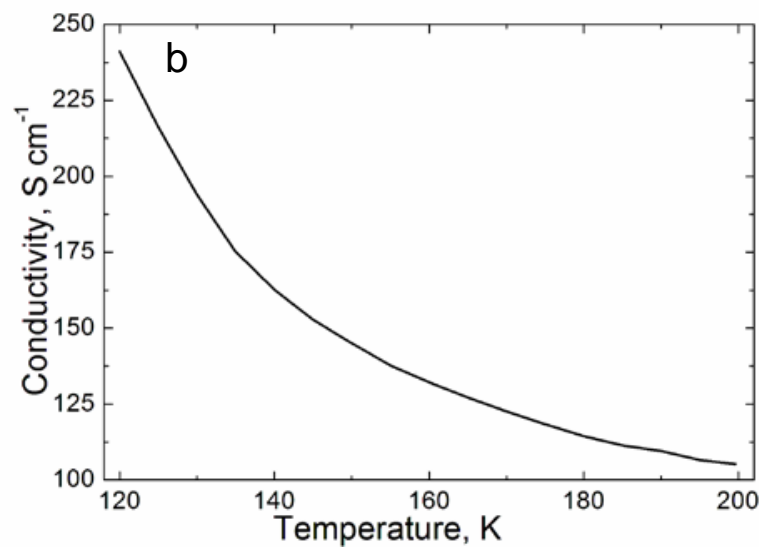

Figure 2. (a) Conductivity of oriented single crystal of $\mathbf{1}$ measured by four-probe technique in anaerobic conditions; (b) microwave conductivity measured in the $200-120 \mathrm{~K}$ range. Inset shows the directions of crystallographic axes in a crystal, advanced crystal surface from which both conductivities were measured is shown by grey color.

CT between $\mathrm{C}_{60} 0^{-}$are manifested in the spectra of the salts at wavenumbers higher than $5500 \mathrm{~cm}^{-1}[6]$. Thus, the band at $2000 \mathrm{~cm}^{-1}$ can be attributed to the intraband transition in metal or CT between $\mathrm{C}_{60}{ }^{0}$ and $\mathrm{C}_{60} 0^{-}$and that well agrees with metallic conductivity in this compound at RT. The $F_{1 \mathrm{u}}(4) \mathrm{C}_{60}$ mode which is sensitive to CT to the fullerene molecule is not well defined and manifested at about $1403 \mathrm{~cm}^{-1}$ (Table S1), that is intermediate position between those characteristic of $\mathrm{C}_{60}{ }^{\circ}$ and $\mathrm{C}_{60}{ }^{\circ-}$.

The electron paramagnetic resonance (EPR) spectra of single crystals with microwave electric field directed parallel to the $(10 \overline{1})$

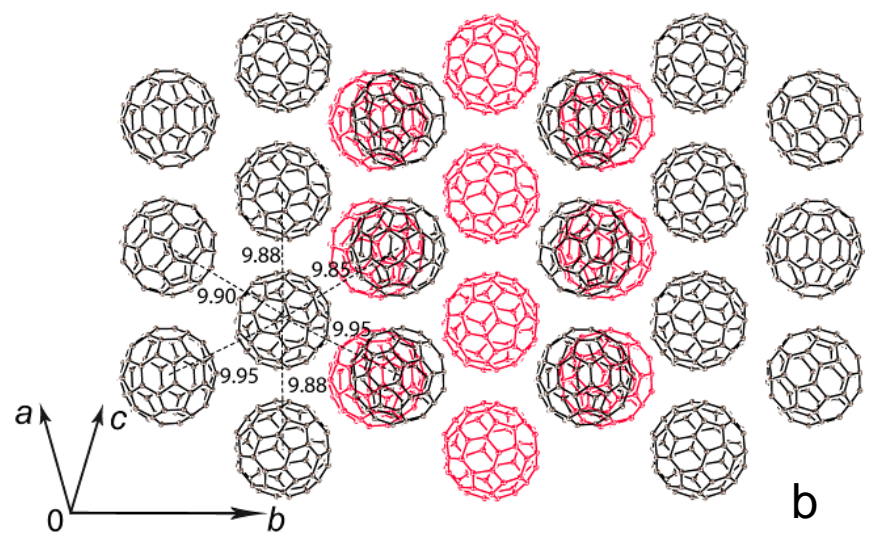

Figure 1. (a) View on crystal structure of $\left\{\right.$ cryptand $\left.\left(\mathrm{Na}^{+}\right)\right\}\left(\mathrm{C}_{60}\right)_{3}{ }^{-} \cdot 2 \mathrm{C}_{6} \mathrm{H}_{4} \mathrm{Cl}_{2}$ (1) along the $a$ axis; (b) view on fragments of hexagonal fullerene layers (fragments located at $z=0.5$ and 1 are drawn in black and red, respectively). Fullerenes, cations and solvent molecules are shown in major orientation. 


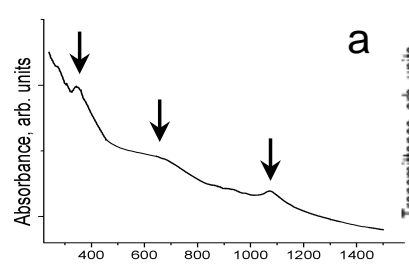

Wavelength, $\mathrm{nm}$

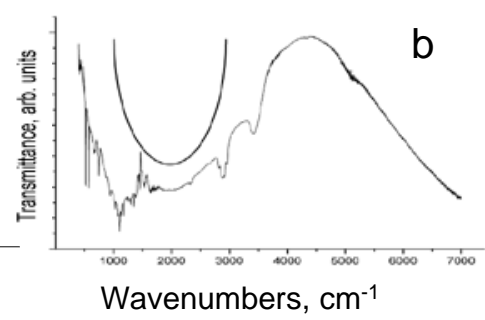

Figure 3. UV-visible-NIR (a) and IR spectra (b) of $\mathbf{1}$ measured in $\mathrm{KBr}$ pellets prepared in anaerobic conditions.

plane showed the signal with $g=1.9966$ and a linewidth $(\Delta H)$ of 3.0 mT (RT) ascribed to $\mathrm{C}_{60}{ }^{\circ}$. The signal has an asymmetric Dysonian shape characteristic of highly conductive materials (Fig. 4, inset). Such EPR signals were observed in quasi-2D organic metals and superconductors based on bis(ethylenedithio)tetrathiafulvalene (ET), e.g. $\left[\beta-(\mathrm{ET})_{2} \mathrm{I}_{3}\right]^{[20]}$ and fullerene, e.g. $\left(\mathrm{MDABCO}^{+}\right)\left(\mathrm{C}_{60^{-}}{ }^{-}\right) \cdot \mathrm{TPC}^{[5]}$. The asymmetry ratio between the maximum and the minimum of the absorption derivative (A/B) depends on crystal and varies from 1.8 to 2.6 at RT. A/B exhibits a gradual increase from 310 down to 180 $\mathrm{K}$ and decreases below this temperature. The abrupt decrease of $\mathrm{A} / \mathrm{B}$ is observed below $120 \mathrm{~K}$ (Fig. 4). Such behavior corresponds well to the temperature dependence of conductivity measured by four-probe technique. It is interesting that the EPR signal from the single crystal with microwave electric field directed parallel to the $(010)$ plane shows a shape close to the Lorentzian one. Therefore, the Dysonian shape of the EPR signal is due to a skin effect. In spite of 3D packing of fullerenes in $\mathbf{1}$, conductivity is anisotropic and that in the $(10 \overline{1})$ is higher than that in the (010) plane. Integral intensity of the almost Lorentzian shaped signal showed a nearly temperature independent behavior down to $120 \mathrm{~K}$ as it should be observed for the metals showing temperature independent Pauli paramagnetism ${ }^{[5]}$. G-factor of the EPR signal is nearly temperature independent in metallic state and increases noticeably at the transition of the complex to the semiconducting state below $120 \mathrm{~K}$ (Fig. 4). The EPR signal linewidth decreases with temperature as in other $\mathrm{C}_{60} 0^{\circ-}$ salts. Slight broadening of the EPR signal below $20 \mathrm{~K}$ can be due to weak magnetic coupling of spins manifested at low temperatures.
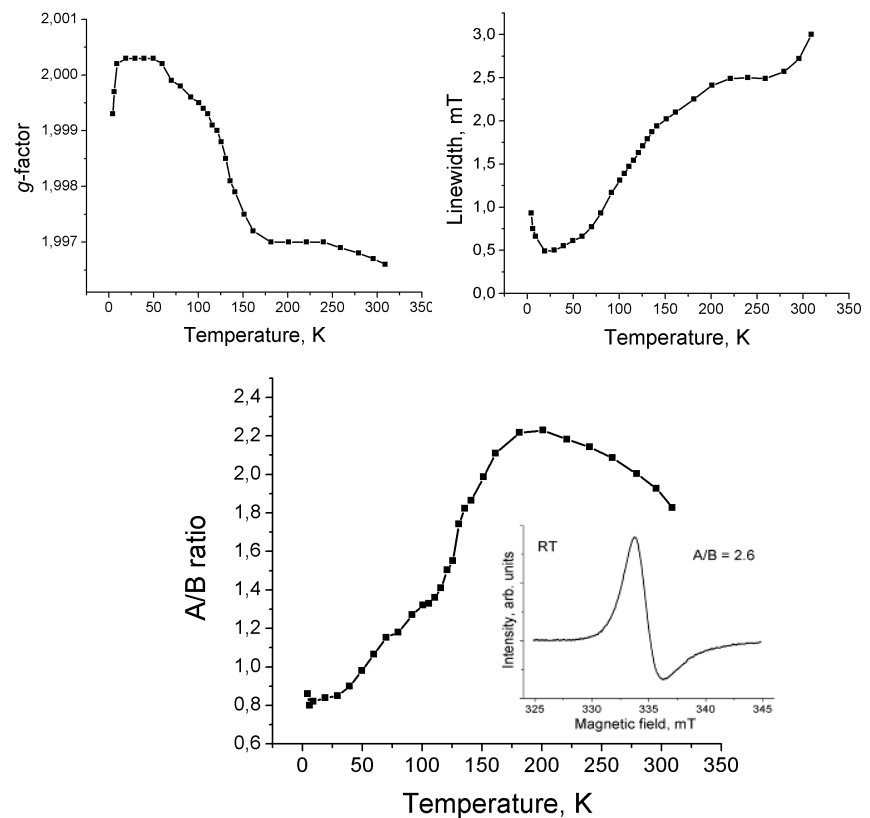

Figure 4. Temperature dependence of $g$-factor, linewidth and the A/B ratio for a single crystal of $\mathbf{1}$. Inset shows Dysonian type EPR signal of $\mathbf{1}$ at room temperature (RT).

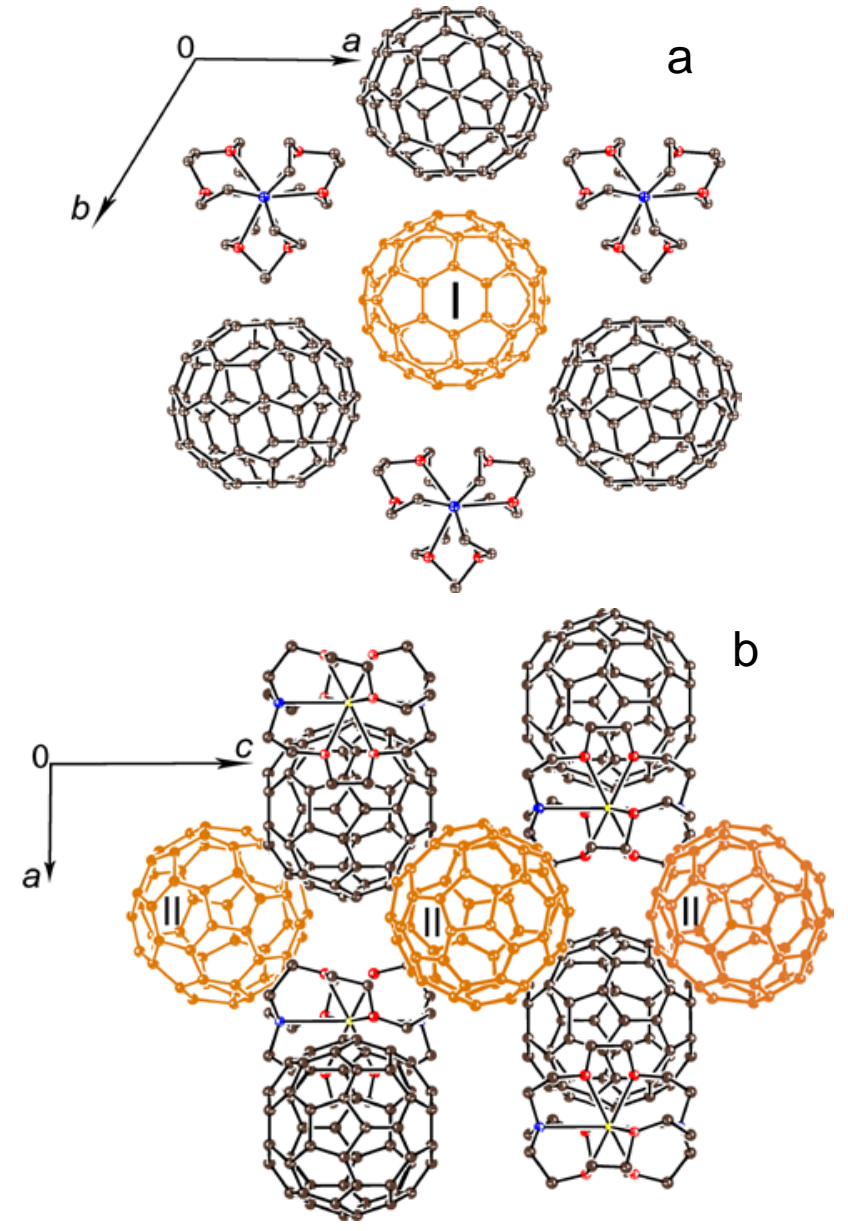

Figure 5. Surrounding of two independent fullerenes of types I and II in $\mathbf{2}$. Only one orientation is shown for the fullerenes and the cryptand $\left(\mathrm{Na}^{+}\right)$ cations.

Exposure of single crystal of $\mathbf{1}$ to air during one month does not change the Dysonian shape of the EPR signal. Therefore, this complex is air stable and metallic conductivity is not affected by air oxidation.

\section{Crystal structure and optical properties of \{cryptand $\left.\left(\mathrm{Na}^{+}\right)\right\}\left(\mathrm{C}_{60}\right)_{2}^{-}$(2)}

Compound 2 was obtained as well-shaped large hexagonal plates. The structure of $\mathbf{2}$ was determined from X-ray diffraction on single crystal. There are two independent $\mathrm{C}_{60}$ of type I and II (Fig. 5) per one cryptand $\left(\mathrm{Na}^{+}\right)$cation in 2 indicating the formation of a complex with -0.5 charge on fullerene as average.

The complex has hexagonal 3D packing of fullerenes in a crystal with short interfullerene ctc distances. Fullerenes of type I (Fig. 5a) are located in the center of a trihedral prism composed of six fullerenes with ctc distances of 9.86 (three neighbors located above fullerene) and $9.93 \AA$ (three neighbors located below fullerene). Fullerenes of type II (Fig. 5b) are located in the center of a distorted prism from six fullerene neighbors. In this case the ctc interfullerene distances are 9.93-9.96 A. Fullerene of type I (Fig. 5a) is surrounded by three cryptand $\left(\mathrm{Na}^{+}\right)$cations with a short distance between the center of $\mathrm{C}_{60}$ and the $\mathrm{Na}^{+}$ions of only $8.446 \AA$. Fullerene of type II (Fig. 5b) is surrounded by four cations, and the distances between the center of $\mathrm{C}_{60}$ and the $\mathrm{Na}^{+}$ions are essentially longer (9.89-9.91 $\AA$ ). These data show that conditions for electrostatic interaction between two independent fullerenes and the cryptand $\left(\mathrm{Na}^{+}\right)$cations are different, and that can result in charge disproportionation in the fullerene framework accompanied by the 
formation of -1 charged (fullerene of type I) and neutral $\mathrm{C}_{60}$ (fullerene of type II).

Indeed, the IR spectrum of 2 supports charge disproportionation due to the presence of the absorption bands of the $F_{1 u}(4) C_{60}$ mode which is sensitive to CT to the fullerene molecule at 1390 and 1429 $\mathrm{cm}^{-1}$ (see Supporting information, Fig. S2). These positions correspond to the presence of -1 and neutral $\mathrm{C}_{60}$ in 2 [21, 22]. The bands in the spectrum of $\mathbf{2}$ in the UV-visible-NIR range at 264, 346 nm were attributed to neutral fullerene whereas the bands at 940 and $1080 \mathrm{~nm}$ were ascribed to $\mathrm{C}_{60}{ }^{-}$(Fig. S5). A weak band in the visible range at $500 \mathrm{~nm}$ can be due to CT between fullerenes in 2 . A lowenergy band in the IR range at about $2000 \mathrm{~cm}^{-1}$ is not observed in the spectrum of $\mathbf{2}$.

Microwave conductivity was measured on single crystal of $\mathbf{2}$ in the 200-5 K range. The single crystal was oriented in such a way that current flew in the $a b$ plane. Since absorption as well as the frequency dependence of microwave absorption were not found in the whole studied temperature range, it can be concluded that the crystal is not metallic that agrees with charge disproportionation which should suppress metallic conductivity.

\section{Crystal structure, optical and magnetic properties of \{cryptand $\left.\left(\mathrm{Na}^{+}\right)\right\}_{8}\left(\mathrm{C}_{60}\right)_{6}{ }^{8-}(3)$}

Complex 3 has a highly symmetric trigonal unit cell with equal parameters $a=b=c=20.1117(5) \AA$. There are two independent cryptand $\left(\mathrm{Na}^{+}\right)$cations: one with full occupancy and the other one located on the 3-fold symmetry axis has 0.33 occupancy. There is also one independent fullerene $\mathrm{C}_{60}$ in $\mathbf{3}$ with full occupancy. As a result, complex 3 has 8 cations per 6 fullerene molecules and average charge on $\mathrm{C}_{60}$ is -1.33 .

This complex shows close 3D packing which can be presented by alternation of the layers of two types along the $a$ axis (Fig. 6) The layers are arranged in such a way that fullerenes from one layer are positioned exactly over the fullerenes from the adjacent layers. VdW C...C contacts between fullerenes are formed in the layers and with fullerenes from the adjacent layers located above and below the layer.

Each fullerene in the crystal structure of $\mathbf{3}$ is surrounded by four fullerene neighbors to form square environment. All four interfullerene ctc distances are equal to $10.056 \AA$ (half of the unit cell parameter) and multiple short $\mathrm{vdW} \mathrm{C} \cdots \mathrm{C}$ contacts are formed between them. Each fullerene has highly symmetric cationic

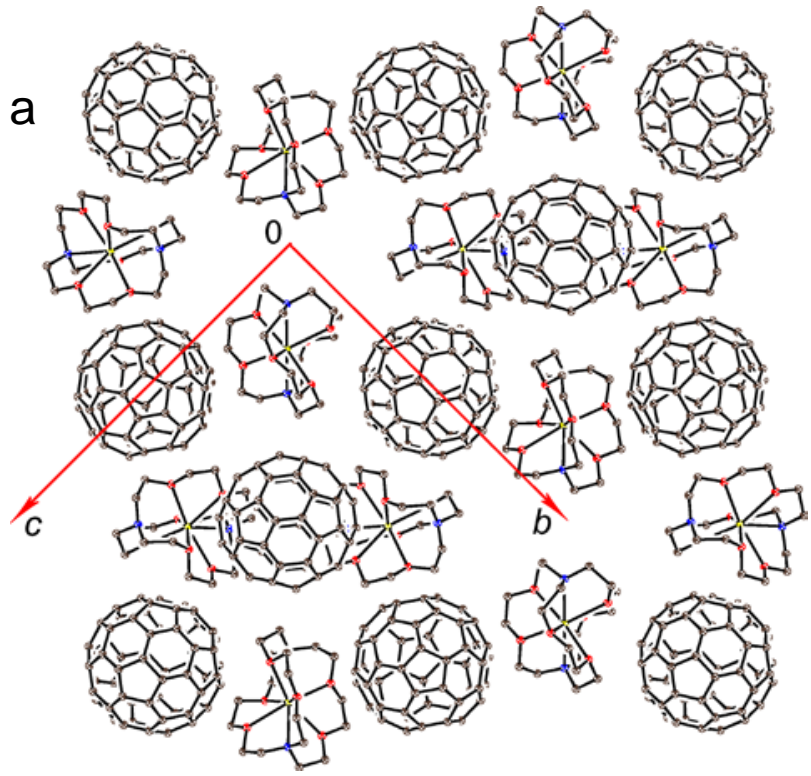

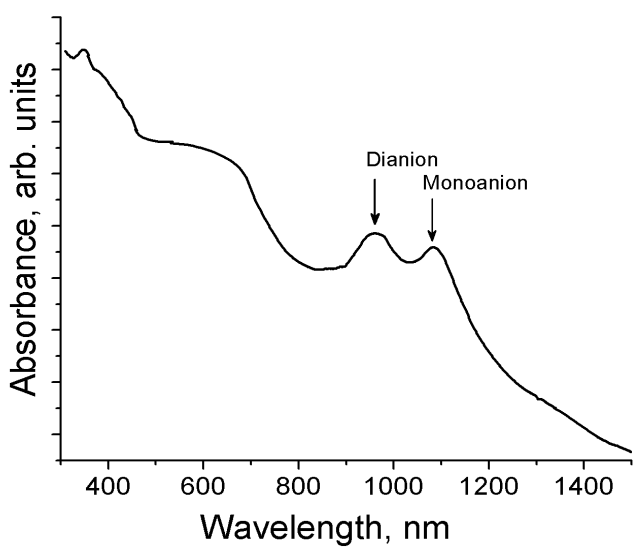

Figure 7. The UV-visible-NIR spectrum of $\mathbf{3}$ in $\mathrm{KBr}$ pellet prepared in anaerobic conditions.

surrounding from eight cryptand( $\left.\mathrm{Na}^{+}\right)$cations in 3 . In contrast to 2, uniform cationic surrounding does not support charge disproportionation in $\mathbf{3}$.

The UV-visible-NIR and IR spectra of $\mathbf{3}$ are shown in Figs. 7 and S3, respectively. Two bands in the NIR range with maxima at 960 and $1080 \mathrm{~nm}$ indicate the presence of -2 and -1 charged fullerenes (Fig. 7). An intense broad band at $660 \mathrm{~nm}$ (Fig. 7) appears most probably due to CT between fullerenes. It is known that the position of $F_{1 u}(4) \mathrm{C}_{60}$ mode is most sensitive to CT to a fullerene molecule and shifts from $1429 \mathrm{~cm}^{-1}$ (neutral $\mathrm{C}_{60}$ ) to 1386-1396 and $1374-1377 \mathrm{~cm}^{-1}$ at the formation of -1 and -2 charged $C_{60}{ }^{[18,21-25]}$. The position of this mode in the IR spectrum of $\mathbf{3}$ at 1385 and about $1377 \mathrm{~cm}^{-1}$ corresponds to the presence of mono- and dianions of C60. Thus, optical spectra support charge disproportionation in $\mathbf{3}$.

To comprehend the magnetic properties of $\mathbf{3}$ magnetic behavior of individual mono- and dianions of $\mathrm{C}_{60}$ should be considered. Generally, monoanions of $\mathrm{C}_{60}$ show broad EPR signals at RT with $g$-factor $=1.996-2.000$ and linewidth $\Delta H=3-6 \mathrm{mT}$. The signals strongly narrow with decreasing temperature. ${ }^{[24-27]}$ Dianions of $C_{60}$ have temperature activated excited triplet state. They show a weak narrow signal below $150 \mathrm{~K}$, and new broad signals with $g$-factor = 2.0004-2.0030 and $\Delta H=2.76-5.60 \mathrm{mT}$ appear above $150-170 \mathrm{~K}$ and their intensity grows with temperature ${ }^{[18,24]}$. The EPR signal of $\mathbf{3}$ is strongly asymmetric in the 295- $4 \mathrm{~K}$ range and can be fitted by three Lorentzian lines as shown in Fig. 8. The temperature dependence of

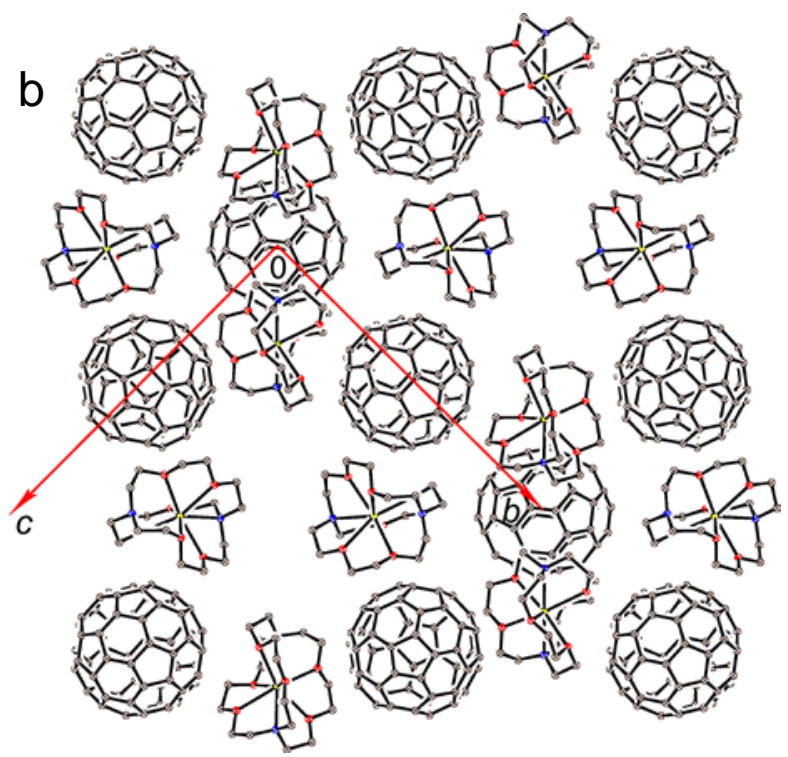

Figure 6. View along the $a$ axis on two adjacent fullerene layers located at $a=0$ (a) and 0.5 (b). These layers separated by cationic cryptand(Na ${ }^{+}$) layer are located one after another along the $a$ axis and form 3D fullerene packing in 3. 

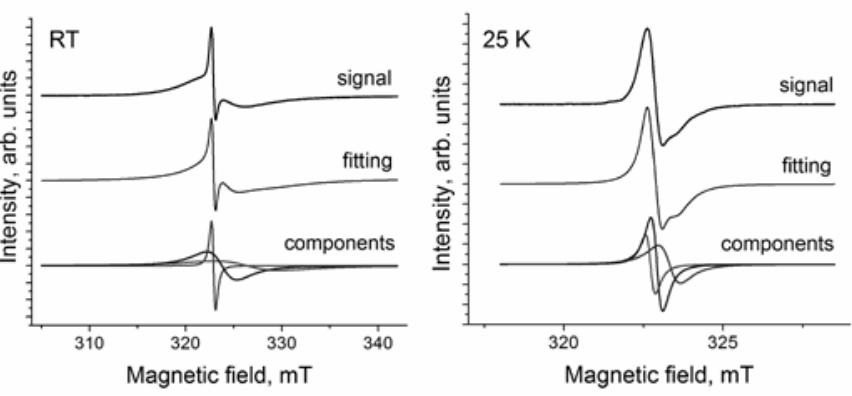

Figure 8. Fitting of EPR signal of polycrystalline 3 at RT and $25 \mathrm{~K}$ by three Lorentzian lines.

total integral intensity of three lines is shown in Fig. 9c. According to Fig. 9c there are two temperature ranges with different behavior. Integral intensity shows a pure paramagnetic dependence increasing with decreasing temperature in the 4-166 K range. Such behavior can be due to the presence of paramagnetic $\mathrm{C}_{60^{\circ-}}$ and the $\mathrm{C}_{60}{ }^{-2}$ dianions with diamagnetic singlet ground state. In this temperature range, the signal can be fitted by three lines with $g_{1}=2.0017$ and $\Delta H$ of $0.37 \mathrm{mT}, g_{2}=1.9989$ and $\Delta H$ of $0.46 \mathrm{mT}$ and $g_{3}=1.9967$ and $\Delta H$ of $1.78 \mathrm{mT}(166 \mathrm{~K})$. The narrow line is specified by temperature independent $g$-factor and linewidth. Similar narrow signals were found in the spectra of $\mathrm{C}_{60^{-}}{ }^{-}$or $\mathrm{C}_{60^{2-}}[18,23,28,29]$. They can appear due to air oxidation of fullerene anions or the presence of impurities. The major two-component signal with $g_{2}$ and $g_{3}$ noticeably narrows with decreasing temperature and can be attributed to $\mathrm{C}_{60}{ }^{\circ}$. The parameters of the signal $25 \mathrm{~K}$ are $g_{2}=2.0007$ and $\Delta H$ of $0.37 \mathrm{mT}$ and $g_{3}=1.9983$ and $\Delta H$ of $0.693 \mathrm{mT}$ (Fig. 8). Integral intensity of the signal strongly grows above $166 \mathrm{~K}$ (Fig. 9c) most probably due to thermal population of the excited triplet state in the $\mathrm{C}_{60}{ }^{-2}$ dianions. That is accompanied by the shift of $g$-factors of two components to lower values and their strong broadening (Figs. 9a and 9b). The RT parameters of these components are $g_{2}=1.9956$ and $\Delta H$ of $3.10 \mathrm{mT}$ and $g_{3}=1.9800$ and $\Delta H$ of $6.74 \mathrm{mT}$. The EPR spectra together with the optical spectra indicate the presence of $\mathrm{C}_{60} 0^{\circ-}$ and $\mathrm{C}_{60} 0^{2-}$ in 3 most probably due to charge disproportionation.

Thus, in spite of similar cationic surrounding differently charged fullerenes with -1 and -2 charges are formed in $\mathbf{3}$. We suppose that mono- and dianions are positionally disordered in a crystal. Therefore, they cannot be resolved by X-ray diffraction and the given $\mathrm{C}_{60}$ molecule is the average one.
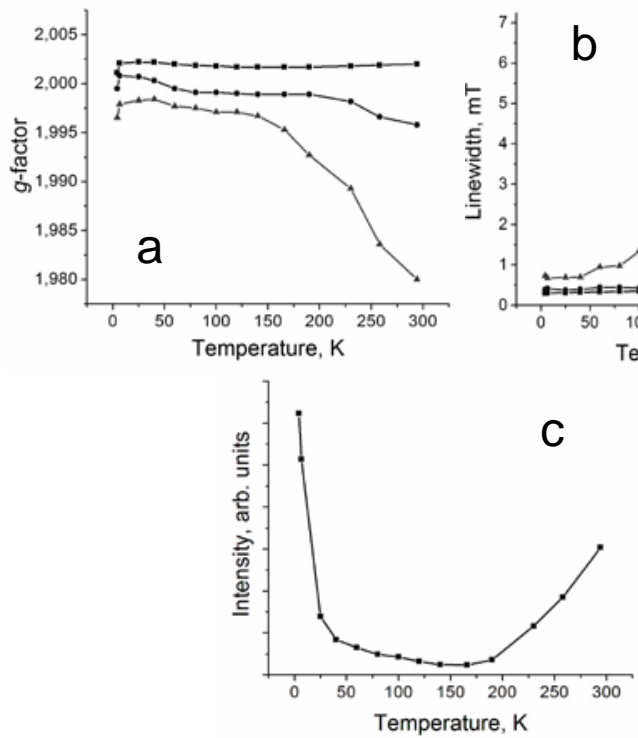

Figure 9. Temperature dependence of $g$-factor (a), linewidth (b) and integral intensity of three components (c) for polycrystalline 3

\section{Crystal structure and optical properties of $\left\{\operatorname{cryptand}\left(\mathrm{Li}^{+}\right)\right\}_{2}\left(\mathrm{C}_{60}{ }^{-}\right)_{2} \cdot \mathrm{C}_{6} \mathrm{H}_{4} \mathrm{Cl}_{2} \cdot \mathrm{C}_{6} \mathrm{H}_{14}(4)$}

Complex 4 was obtained with the cryptand $\left(\mathrm{Li}^{+}\right)$counter cations without addition of $\mathrm{Fe}^{\mathrm{II}} \mathrm{TPyzPzEt}$. The crystal structure determined at $120 \mathrm{~K}$ showed the presence of two cryptand $\left(\mathrm{Li}^{+}\right)$cations per two fullerene units and this salt has full -1 charge on fullerene. X-ray diffraction data also show that the $\mathrm{C}_{60}{ }^{\circ-}$ radical anions are dimerized forming singly bonded $\left(\mathrm{C}_{60}{ }^{-}\right)_{2}$ dimers. The intercage $\mathrm{C}-\mathrm{C}$ bond length is $1.602(8)$ and the interfullerene ctc distance is $9.3 \AA$ as in other singly bonded $\left(\mathrm{C}_{60}{ }^{-}\right)_{2}$ dimers ${ }^{[16,29-34]}$. The crystal structure of monomeric high-temperature phase of $\mathbf{4}$ cannot be solved due to disorder.

The optical spectrum of $\mathbf{4}$ corresponds to the presence of the $\mathrm{C}_{60}{ }^{\circ-}$ radical anions due to that $F_{1 u}(4) \mathrm{C}_{60}$ mode appears as a single band at $1390 \mathrm{~cm}^{-1}$ and intense bands of $\mathrm{C}_{60}{ }^{-}$are manifested in the NIR range at 935 and $1072 \mathrm{~nm}$ (Figs. S4 and S6, respectively).

The salt manifests an intense EPR signal which can be fitted by narrow and broad components with $g_{1}=2.0002$ and $\Delta H$ of $0.51 \mathrm{mT}$ and $g_{2}=1.9915$ and $\Delta H$ of $3.18 \mathrm{mT}$ (RT). The broad component is ascribed to $\mathrm{C}_{60}{ }^{\circ}$. The broad component decreases strongly in intensity below $250 \mathrm{~K}$ due to dimerization of $\mathrm{C}_{60} 0^{-}$and the formation of diamagnetic and EPR silent singly bonded $\left(\mathrm{C}_{60}{ }^{-}\right)_{2}$ dimers. Previously, similar behavior was observed in many complexes and salts of $\mathrm{C}_{60^{\circ-}}$ with close fullerene packing ${ }^{[16,29-34]}$.

Dimerization of $\mathrm{C}_{60} 0^{-}$, which most probably involves electrons from the singly occupied molecular orbital (SOMO) of $\mathrm{C}_{60}{ }^{\circ-}$ results in the formation of a stable two-electron intercage $\mathrm{C}-\mathrm{C}$ bond and the transition of the compounds from paramagnetic to the diamagnetic state. Since only one of two or three fullerene molecules has electron on SOMO of $\mathrm{C}_{60}$ in $\mathbf{1}$ and $\mathbf{2}$ with noninteger CT, no stable intercage $\mathrm{C}-\mathrm{C}$ bonds are formed in this case and dimerization is not realized.

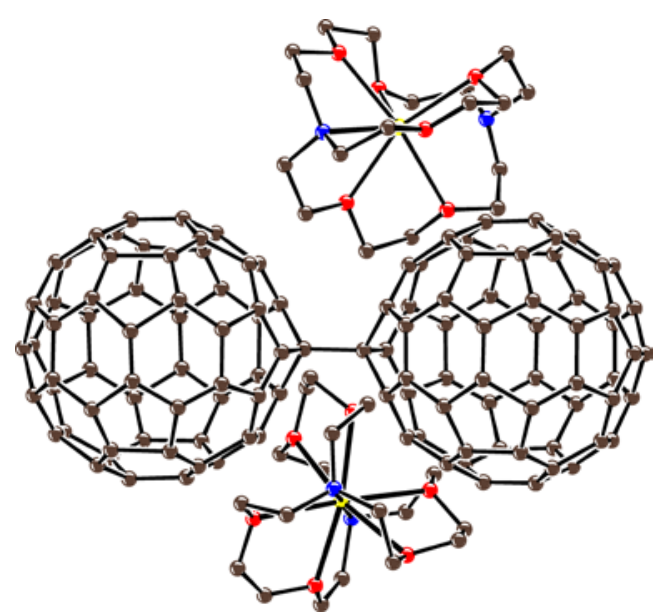

Figure 10. Crystal structure of dimeric phase of 4 at $120 \mathrm{~K}$. Solvent molecules are not shown.

\section{Conclusion}

In this work we report on the new approach developed by us for the synthesis of crystalline fullerene complexes with noninteger average CT to the fullerene molecule ( $\delta=-0.33,-0.5$ and -1.33 ) by oxidation of the salts with -1 and -2 charged fullerenes by iron(II) octaethyltetrapyrazinoporphyrazine. Depending of cationic surrounding, charges can be delocalized over fullerenes providing highly conducting metallic state in $\mathbf{1}$ or charge disproportionation is observed with the appearance of differently charged fullerenes in a crystal: neutral and -1 charged fullerenes in 2 , and -1 and -2 
charged fullerenes in 3. Complex $\mathbf{1}$ preserves metallic properties in the air allowing us to obtain air stable fullerene metal. We also found that no dimerization of fullerenes is observed in $\mathbf{1}$ and 2 though fullerenes are closely packed in crystals. Such peculiarities make fullerene complexes with noninteger CT to fullerene promising candidates to develop highly conducting air stable fullerene materials. Metallic state can realize in them at uniform cationic surrounding of fullerenes and the absence of charge disproportionation.

\section{Acknowledgements}

The work was supported by Russian Science Foundation (Grant 14-1300028) and Grant-in-Aid Scientific Research from JSPS, Japan (23225005 and 26288035). PAS and MMS are thankful to Russian Science Foundation (Grant 14-23-00204) for support in synthesis and electrochemical study of iron(II) octaethyltetrapyrazinoporphyrazine.

[1] A. F. Hebard, M. J. Rosseinsky, R. C. Haddon, D. W. Murphy, S. H. Glarum, T. T. M. Palstra, A. P. Ramirez, A. R. Kortan, Nature 1991, 350, 600-601.

[2] K. Tanigaki, K. Prassides, J. Mater. Chem. 1995, 5, 1515-1527

[3] A.Y. Ganin, Y. Takabayashi, P. Jeglič, D. Arčon, A. Potocnik, P.J. Baker, Y. Ohishi, M. T. McDonald, M.D. Tzirakis, A. McLennan, G.R. Darling, M. Takata, M.J. Rosseinsky, K. Prassides, Nature 2010, 466, 221-225.

[4] F. Bommeli, L. Degiorgi, D. Wachter, Ö. Legeza, A. Jánossy, G. Oszlanyi, O. Chauvet, L. Forro, Phys. Rev. B 1995, 51, 14794-14797.

[5] D. V. Konarev, S. S. Khasanov, A. Otsuka, M. Maesato, G. Saito, R. N. Lyubovskaya, Angew. Chem. Int. Ed. 2010, 49, 4829-4832.

[6] D. V. Konarev, S. S. Khasanov, A. Otsuka, M. Maesato, M. Uruichi, K. Yakushi, A. Shevchun, H. Yamochi, G. Saito, R. N. Lyubovskaya, Chem. Eur. J. 2014, 20, 7268-7277.

[7] A. Kromer, U. Wedig, E. Roduner, M. Jansen, K. Yu. Amsharov, Angew. Chem. Int. Ed. 2013, 52, 12610-12614.

[8] a) J. M. Williams, J. R. Ferraro, R. J. Thorn, K. D. Carlson, U. Geiser, H. H. Wang, A.M. Kini, M.- H. Whangbo. Organic Superconductors (including Fullerenes). Synthesis, Structure, Properties and Theory, Prentice Hall, New Jersey: Englewood Cliffs, 1992; b) T. Ishiguro, G. Saito, K. Yamaji, Organic Superconductors 2-nd edn., Springer Ser. In Solid-State Sci. Vol. 51. Berlin, Heidelberg, New York, 1998, pp. 1522; c) G. Saito, Y. Yoshida, Chem. Record 2011, 11, 124-145

[9] T. Inabe, H. Tajima, Chem. Rev. 2004, 104, 5503-5534.

[10] a) I.F. Shchegolev, Phys. Status Solidi A, 1972, 12, 9-45; J. S. Pedersen, K. Carneiro, Rep. Prog. Phys. 1987, 50, 995-1043.

[11] P. Cassoux, L. Valade, H. Kobaayashi, A. Kobayashi, R.A. Clark, A.E. Underhill, Coord. Chem. Rev. 1991, 110, 115-160.

[12] H. Kobayashi, H. Tomita, H. Moriyama, A. Kobayashi, T. Watanabe, J. Am. Chem. Soc. 1994, 116, 3153-3154.

[13] a) H. Moriyama, H. Kobayashi, A. Kobayashi, T. Watanabe, Chem.
Phys. Lett. 1995, 238, 116-121; b) H. Moriyama, M. Abe, H. Motoki, T. Watanabe, S. Hayashi, H. Kobayashi, Synth. Met. 1998, 94, 167171

[14] D. V. Konarev, S. S. Khasanov, A. Otsuka, H. Yamochi, G. Saito, R. N. Lyubovskaya, Inorg. Chem. 2014, 53, 6850-6855.

[15] D. V. Konarev, S. S. Khasanov, G. Saito, R. N. Lyubovskaya, Cryst. Growth Des. 2009, 9, 1170-1181.

[16] N. V. Kozhemyakina, K. Y. Amsharov, J. Nuss, M. Jansen, Chem. Eur. J. 2011, 17, $1798-1805$.

[17] I. Noviandri, R. D. Bolskar, P. A. Lay, C. A. Reed, J. Phys.Chem. B 1997, 101, 6350-6358.

[18] D. V. Konarev, A. V. Kuzmin, S. V. Simonov, S. S. Khasanov, E. I. Yudanova, G. Saito, R. N. Lyubovskaya, Phys. Chem. Chem. Phys. 2013, 15, 9136-9144.

[19] H. J. Byrne, in Progress in Fullerene Research, Eds H. Kuzmany, J. Fink, M. Mehring, S. Roth, Singapore: World Scientific, 1995, p. 183195.

[20] T. Sugano, G. Saito, M. Kinoshita, Phys. Rev. B. 1986, 34, 117-125.

[21] T. Picher, R. Winkler, H. Kuzmany, Phys. Rev. B 1994, 49, 15879 15889.

[22] V. N. Semkin, N. G. Spitsina, S. Krol, A. Graja, Chem. Phys. Lett. 1996, 256, 616-622.

[23] D. V. Konarev, S. S. Khasanov, G. Saito, I. I. Vorontsov, A. Otsuka, R. N. Lyubovskaya, Yu. M. Antipin, Inorg. Chem., 2003, 42, 37063708.

[24] D. V. Konarev, R. N. Lyubovskaya, Russ. Chem. Rev. 2012, 81, 336366.

[25] C.A. Reed, R.D. Bolskar, Chem. Rev. 2000, 100, 1075-1120.

[26] A. Pènicaud, A. Peréz-Benítez, R. Gleason V., E. Muñoz P, R. Escudero, J.Am.Chem.Soc. 1993, 115, 10392-10393.

[27] D. V. Konarev, A. Yu. Kovalevsky, S. S. Khasanov, G. Saito, A. Otsuka, R. N. Lyubovskaya, Eur. J. Inorg. Chem., 2005, 4822-4828.

[28] A. L. Litvinov, D. V. Konarev, E. I. Yudanova, M. G. Kaplunov, R. N. Lyubovskaya, Russ. Chem. Bull. 2002, 51, 2003-2007.

[29] D. V. Konarev, S. S. Khasanov, G. Saito, A. Otsuka, Y. Yoshida, R.N. Lyubovskaya, J. Am. Chem. Soc. 2003, 125, 10074-10083.

[30] D. V. Konarev, S. S. Khasanov, A. Y. Kovalevsky, G. Saito, A Otsuka, R. N. Lyubovskaya, Dalton Trans., 2006, 3716-3720.

[31] D. V. Konarev, S. S. Khasanov, A. Otsuka, G. Saito, R. N. Lyubovskaya. Inorg. Chem. 2007, 46, 2261-2271.

[32] E. A. Schupak, D. M. Lyubov, E. V. Baranov, G. K. Fukin, O. N Suvorova, A. A. Trifonov, Organomet. 2010, 29, 6141-6144

[33] D. V. Konarev, S. S. Khasanov, G. Saito, A. Otsuka, R. N. Lyubovskaya, J. Mater. Chem. 2007, 17, 4171-4177.

[34] D. V. Konarev, S. S. Khasanov, R. N. Lyubovskaya, Russ. Chem. Bull. 2007, 56, 371-392.

Received: ((will be filled in by the editorial staff))

Revised: ((will be filled in by the editorial staff)) Published online: ((will be filled in by the editorial staff)) 


\section{Entry for the Table of Contents}

C60 metal with partial charge transfer

D. V. Konarev,* S. S. Khasanov, M. Ishikawa, E. I. Yudanova, A. F. Shevchun, M. S. Mikhailov, P.A. Stuzhin, A. Otsuka, H. Yamochi, G. Saito, R. N. Lyubovskaya Page Page

Metallic conductivity versus charge disproportionation in the $\mathrm{C}_{60}$ complexes with noninteger average charge on fullerene
Complexes $\left\{\right.$ cryptand $\left.\left(\mathrm{M}^{+}\right)\right\}:\left(\mathrm{C}_{60}\right)$ with full and partial charge transfer

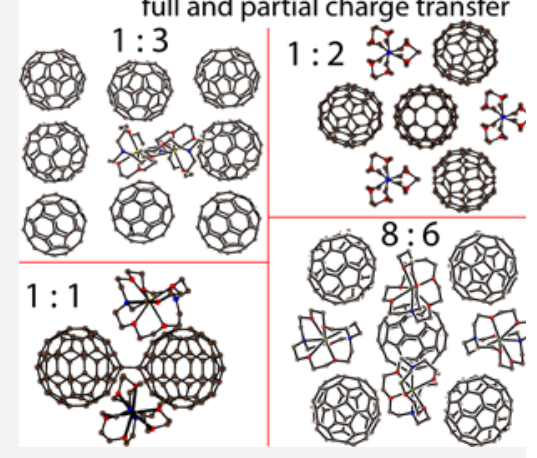

A series of complexes with noninteger average charge on fullerene is obtained. $\left\{\right.$ Cryptand $\left.\left(\mathrm{Na}^{+}\right)\right\}\left(\mathrm{C}_{60}\right)_{3}{ }^{-} \cdot 2 \mathrm{C}_{6} \mathrm{H}_{4} \mathrm{Cl}_{2}$ with partial -0.33 charge on $\mathrm{C}_{60}$ shows metallic behavior down to $150-120 \mathrm{~K}$ which is preserved after one month exposure to air. $\left\{\right.$ Cryptand $\left.\left(\mathrm{Na}^{+}\right)\right\}\left(\mathrm{C}_{60}\right)_{2}{ }^{-}$ (2) and $\left\{\text { cryptand }\left(\mathrm{Na}^{+}\right)\right\}_{8}\left(\mathrm{C}_{60}\right)_{6}{ }^{8-}$ (3) with average -0.5 and -1.33 charges on $\mathrm{C}_{60}$ are nonmetals due to charge disproportionation. No dimerization of $\mathrm{C}_{60}$ is observed in 1-2 in spite of close fullerene packing. The $\left(\mathrm{C}_{60}{ }^{-}\right)_{2}$ dimers are formed in \{cryptand $\left.\left(\mathrm{Li}^{+}\right)\right\}_{2}\left(\mathrm{C}_{60}{ }^{-}\right)_{2} \cdot \mathrm{C}_{6} \mathrm{H}_{4} \mathrm{Cl}_{2} \cdot \mathrm{C}_{6} \mathrm{H}_{14}$ (4) with full -1 charge on $\mathrm{C}_{60}$. 


\section{Supporting information}

\section{Electrochemistry for $\mathrm{Fe}^{\mathrm{II}} \mathrm{TPyzPzE}_{8}$}

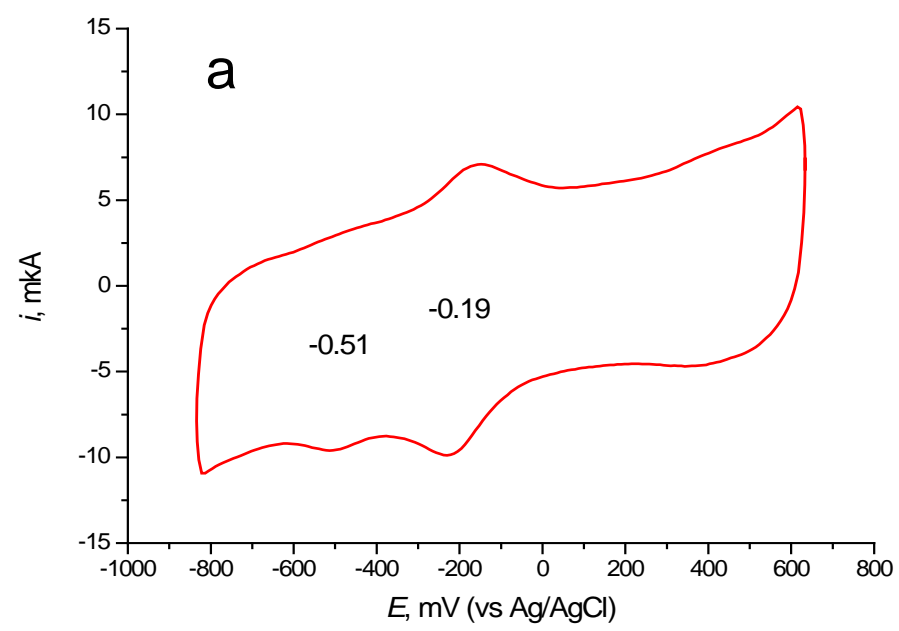

b

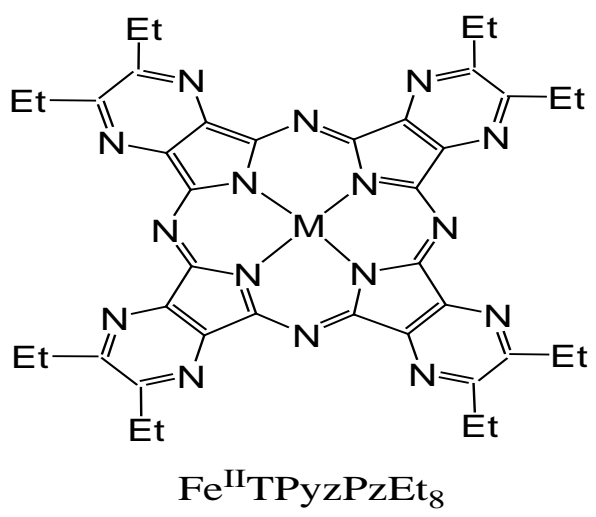

Figure S1. (a) Cyclic voltammogram of $\mathrm{Fe}^{\mathrm{II}} \mathrm{TPyzPzEt}_{8}$ in DMSO containing $0.1 \mathrm{M}$ TBAP; 100 $\mathrm{mV} / \mathrm{s}$ potential scan rate. (b) Molecular structure of $\mathrm{Fe}^{\mathrm{II}} \mathrm{TPyzPzE}_{8}$.

$\mathrm{Fe}^{\mathrm{II}} \mathrm{TPyzPzEt}_{8}$ undergoes two reduction processes in coordinating DMSO leading to monoanionic forms (Figure S1). The $1^{\text {st }}$ well-defined reduction wave observed at $\mathrm{E}^{1 / 2}=-0.19 \mathrm{~V} v \mathrm{~s}$ $\mathrm{Ag} / \mathrm{AgCl}$ can be assigned to the $\mathrm{Fe}^{\mathrm{II}} / \mathrm{Fe}^{\mathrm{I}}$ reduction couple and the formation of $\left[\mathrm{Fe}^{\mathrm{I}} \mathrm{TPyzPz}(2-) \mathrm{Et}_{8}\right]^{-}$. Less intense irreversible reduction observed at cathodic potential of $-0.51 \mathrm{~V}$ vs Ag/AgCl (Figure S1) corresponds very likely to the reduction of the macrocycle and the formation of the $\left[\mathrm{Fe}^{\mathrm{II}} \mathrm{TPyzPz}(3-) \mathrm{Et}_{8}\right]^{]^{--}}$radical anions since this value is similar to that of the $1^{\text {st }}$ reduction potential for the complexes of alkyl substituted TPyzPzs with redox-inactive metals $(-0.50--0.55 \mathrm{~V}[1,2])$. The irreversibility of this process for $\mathrm{Fe}^{\mathrm{II}} \mathrm{TPyzPzEt}_{8}$ and the absence of the corresponding anodic wave might be explained by valence isomerism of $\left.\left[\mathrm{Fe}^{\mathrm{II}} \mathrm{TPyzPz}(3-) \mathrm{Et}_{8}\right)\right]^{\bullet-}$. The isomerisation in coordinating DMSO involves transfer from the hexacoordinated $\mathrm{d}^{6}$ radical anion $\left[\mathrm{Fe}^{\mathrm{II}} \mathrm{TPyzPzEt}_{8}(3-)\left(\mathrm{DMSO}_{2}\right]^{\bullet-}\right.$ to more stable pentacoordinated $\mathrm{d}^{7}$ anion [Fe $\left.{ }^{\mathrm{I}} \mathrm{TPyzPzEt}_{8}(2-)(\mathrm{DMSO})\right]^{-}$. The reversible formation of dianion is seen at $-0.95 \mathrm{~V}$ vs $\mathrm{Ag} / \mathrm{AgCl}$, i.e. at potential value similar to that of the dianion of the $\mathrm{Co}^{\mathrm{I}}$ complex $\left[\mathrm{Co}^{\mathrm{I}} \mathrm{TPyzPzEt}_{8}(3-)\right]^{2-}[3]$ and $\pi$-dianions of alkyl substituted TPyzPzs with redox-inactive metals $\left[\mathrm{M}^{\mathrm{II}} \operatorname{TPyzPz}_{8} \operatorname{Pr}_{8}(4-)\right]^{2-}(\mathrm{M}=\mathrm{Ni}$, Pd, Pt, -0.91 - $-0.93 \mathrm{~V}$ [1]). The formation of dianionic forms of metal phthalocyanines is observed at more negative potentials by $0.2-0.3 \mathrm{~V}$ [4].

\section{References}

[1] K. Takahashi, Y. Aoki, T. Sugitani, F. Moriyama, Y. Tomita, M. Handa, K. Kasuga, K. Sogabe, Inorg. Chim. Acta 1992, 201, 247-249.

[2] K. Ohta, T. Watanabe, T. Fujimoto, I. Yamamoto, J. Chem. Soc., Chem. Commun. 1989, 16111613.

[3] S. Dong, B. Liu, J. Liu, N. Kobayashi, J. Porphyrins Phthalocyanines 1997, 1, 333-340. 
[4] A. B. P. Lever, E. R. Milaeva, G. Speier The redox chemistry of metallophthalocyanines. In

Phthalocyanines: Properties and Applications. Vol. 3, VCH Publishing, Weinheim. Pages 1- 70.

\begin{tabular}{|c|c|c|c|c|c|}
\hline & $\begin{array}{c}\text { Cryptand } \\
{[2,2,2]}\end{array}$ & $\begin{array}{c}\left\{\text { cryptand }[2,2,2]\left(\mathrm{Na}^{+}\right)\right\} \\
\left(\mathrm{C}_{60}\right)_{3}^{-} \\
\cdot 2 \mathrm{C}_{6} \mathrm{H}_{4} \mathrm{Cl}_{2}(\mathbf{1})\end{array}$ & $\begin{array}{c}\left\{\text { cryptand }[2,2,2]\left(\mathrm{Na}^{+}\right)\right\} \\
\left(\mathrm{C}_{60}\right)_{2}^{-}{ }^{-}(\mathbf{2})\end{array}$ & $\begin{array}{c}\left\{\text { cryptand }[2,2,2]\left(\mathrm{Na}^{+}\right)\right\}_{8} \\
\left(\mathrm{C}_{60}\right)_{6}{ }^{8-}(3)\end{array}$ & $\begin{array}{c}\left\{\text { cryptand }[2,2,2]\left(\mathrm{Na}^{+}\right)\right\}_{2} \\
\left(\mathrm{C}_{60}{ }^{-}\right)_{2} \\
\cdot \mathrm{C}_{6} \mathrm{H}_{4} \mathrm{Cl}_{2} \cdot \mathrm{C}_{6} \mathrm{H}_{14} \text { (4) }\end{array}$ \\
\hline Cryptand & $\begin{array}{c}423 \mathrm{w} \\
476 \mathrm{w} \\
528 \mathrm{w} \\
581 \mathrm{w} \\
735 \mathrm{~m} \\
- \\
922 \mathrm{~m} \\
948 \mathrm{w} \\
982 \mathrm{~m} \\
1038 \mathrm{w} \\
1071 \mathrm{~m} \\
1100 \mathrm{~s} \\
1127 \mathrm{~s} \\
1213 \mathrm{w} \\
1295 \mathrm{~m} \\
1329 \mathrm{~m} \\
1360 \mathrm{~s} \\
1446 \mathrm{~m} \\
1462 \mathrm{~m} \\
1490 \mathrm{w} \\
2790 \mathrm{w}\end{array}$ & $\begin{array}{c}423 \mathrm{w} \\
482 \mathrm{w} \\
525 \mathrm{~s}^{*} \\
575 \mathrm{~m}^{*} \\
- \\
746 \mathrm{~m}^{*} \\
924 \mathrm{~m} \\
946 \mathrm{~m} \\
- \\
1034 \mathrm{w}^{*} \\
1077 \mathrm{~m} \\
1103 \mathrm{~s} \\
1129 \mathrm{~m} \\
1236 \mathrm{w} \\
1296 \mathrm{~m} \\
- \\
1355 \mathrm{~m} \\
- \\
1454 \mathrm{~m} * \\
1475 \mathrm{~m} \\
2812 \mathrm{w}\end{array}$ & $\begin{array}{c}- \\
- \\
526 \mathrm{~s}^{*} \\
576 \mathrm{~s}^{*} \\
738 \mathrm{w} \\
747 \mathrm{w} \\
932 \mathrm{w} \\
939 \mathrm{w} \\
- \\
1032 \mathrm{w} \\
- \\
1103 \mathrm{~s} \\
1134 \mathrm{~m} \\
1242 \mathrm{w} \\
1298 \mathrm{~m} \\
- \\
1355 \mathrm{~s} \\
1440 \mathrm{w} \\
1454 \mathrm{~m} \\
1481 \mathrm{w} \\
2813 \mathrm{w} \\
\end{array}$ & $\begin{array}{c}423 \mathrm{w} \\
476 \mathrm{w} \\
527 \mathrm{w}^{*} \\
574 \mathrm{~s}^{*} \\
- \\
748 \mathrm{w} \\
933 \mathrm{~m} \\
940 \mathrm{~m} \\
- \\
1030 \mathrm{w} \\
1080 \mathrm{~m} \\
1102 \mathrm{~s} \\
1135 \mathrm{~m} \\
1239 \mathrm{w} \\
1299 \mathrm{~m} \\
- \\
1355 \mathrm{~s} \\
1440 \mathrm{~m} \\
1454 \mathrm{~m} \\
1480 \mathrm{~m} \\
2794 \mathrm{w}\end{array}$ & $\begin{array}{c}422 \mathrm{w} \\
466 \mathrm{w} \\
525 \mathrm{w}^{*} \\
575 \mathrm{~s}^{*} \\
- \\
751 \mathrm{~m}^{*} \\
932 \mathrm{~m} \\
943 \mathrm{~m} \\
- \\
1033 \mathrm{w}^{*} \\
- \\
1103 \mathrm{~s} \\
1135 \mathrm{~m} \\
1239 \mathrm{w} \\
1297 \mathrm{~m} \\
- \\
1353 \mathrm{~s} \\
- \\
1455 \mathrm{~m} * \\
1478 \mathrm{w} \\
2813 \mathrm{w}\end{array}$ \\
\hline
\end{tabular}

\section{IR-spectra}




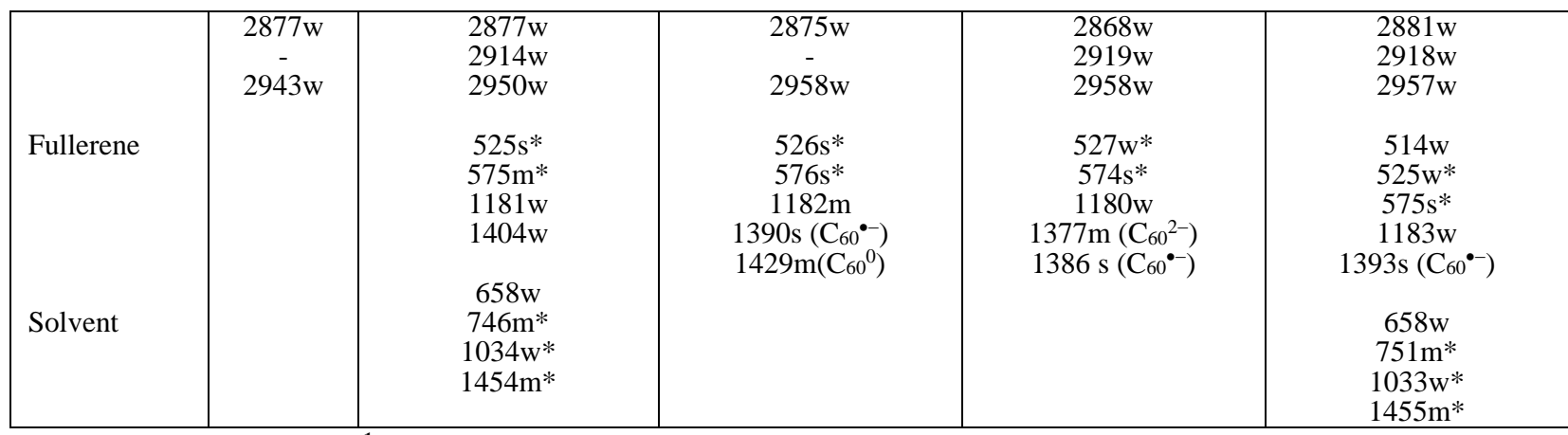

Table S1 IR-spectra $\left(\mathrm{cm}^{-1}\right.$ in $\left.\mathrm{KBr}\right)$ of starting compounds and complexes 1-4.

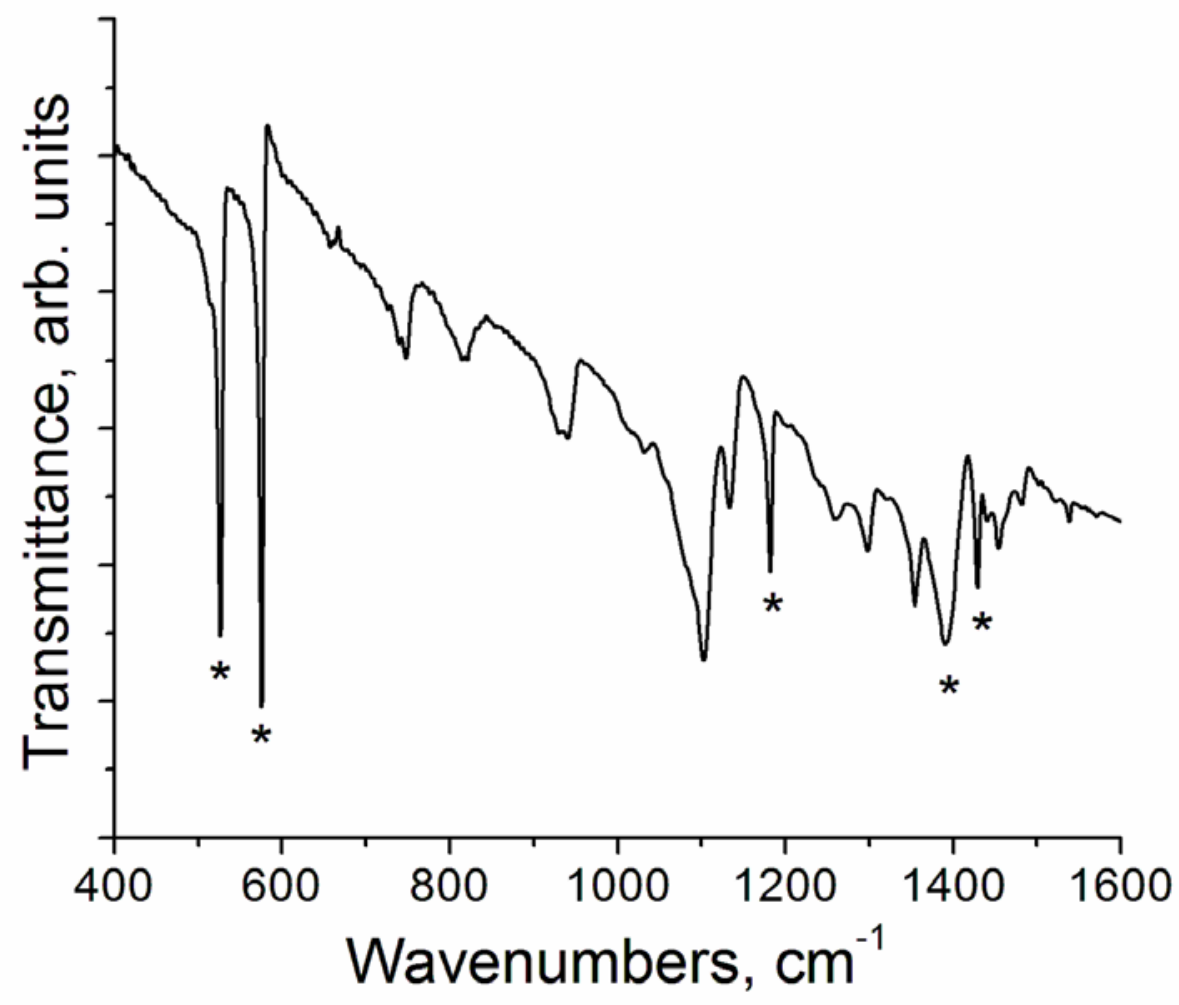

Figure S2. IR-spectrum of $\left\{\right.$ cryptand $\left.[2,2,2]\left(\mathrm{Na}^{+}\right)\right\}\left(\mathrm{C}_{60}\right) 2^{-}$(2) in $\mathrm{KBr}$ pellet prepared in anaerobic conditions. Absorption bands of $\mathrm{C}_{60}$ are marked by asterisks. 


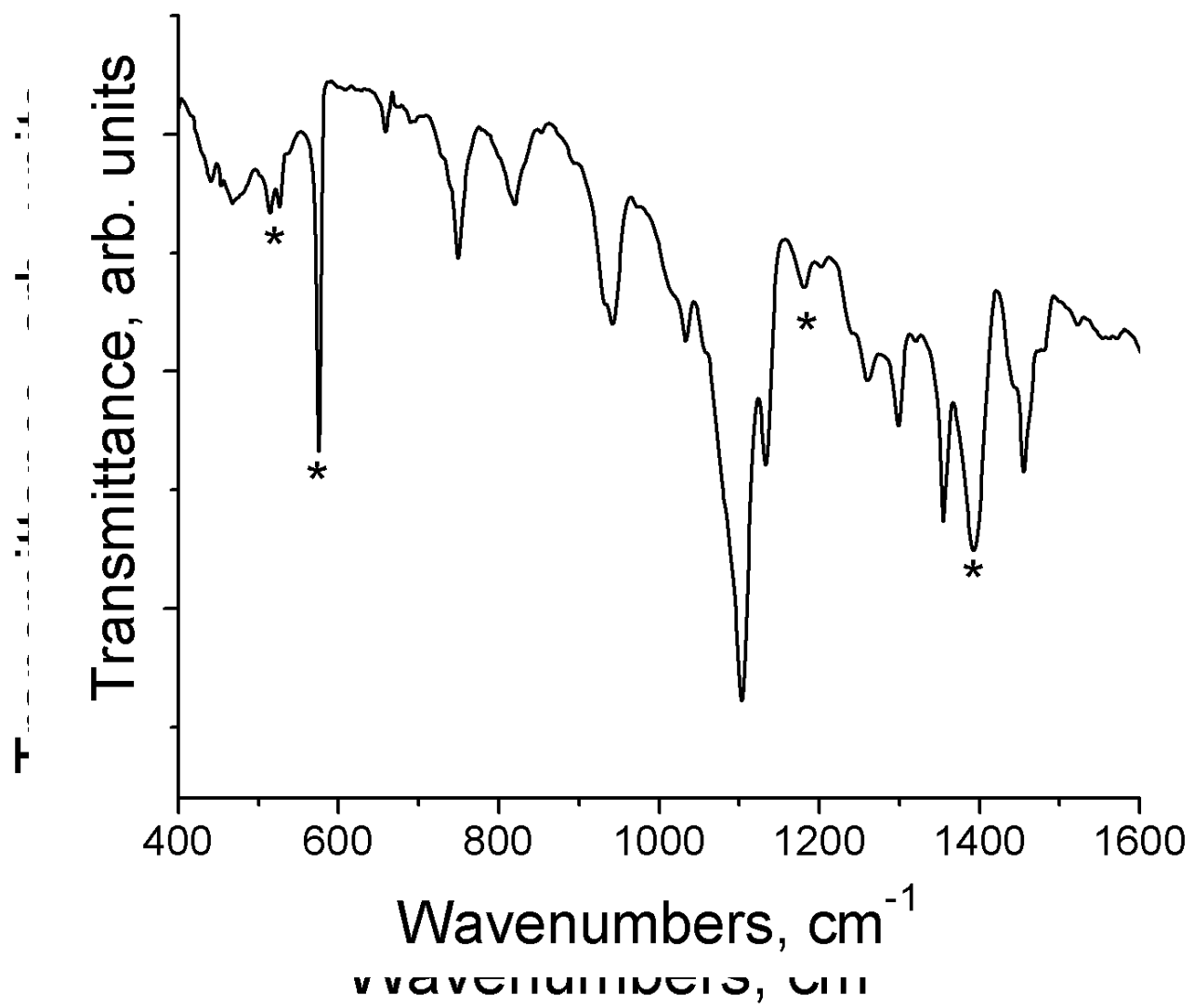

Figure S4. IR-spectrum of $\left\{\text { cryptand[2,2,2] }\left(\mathrm{Na}^{+}\right)\right\}_{2}\left(\mathrm{C}_{60}\right)_{2} \cdot \mathrm{C}_{6} \mathrm{H}_{4} \mathrm{Cl}_{2} \cdot \mathrm{C}_{6} \mathrm{H}_{14}$ (4) in $\mathrm{KBr}$ pellet

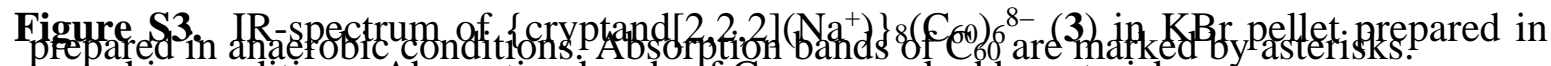
anaerobic conditions. Absorption bands of $\mathrm{C}_{60}$ are marked by asterisks. 

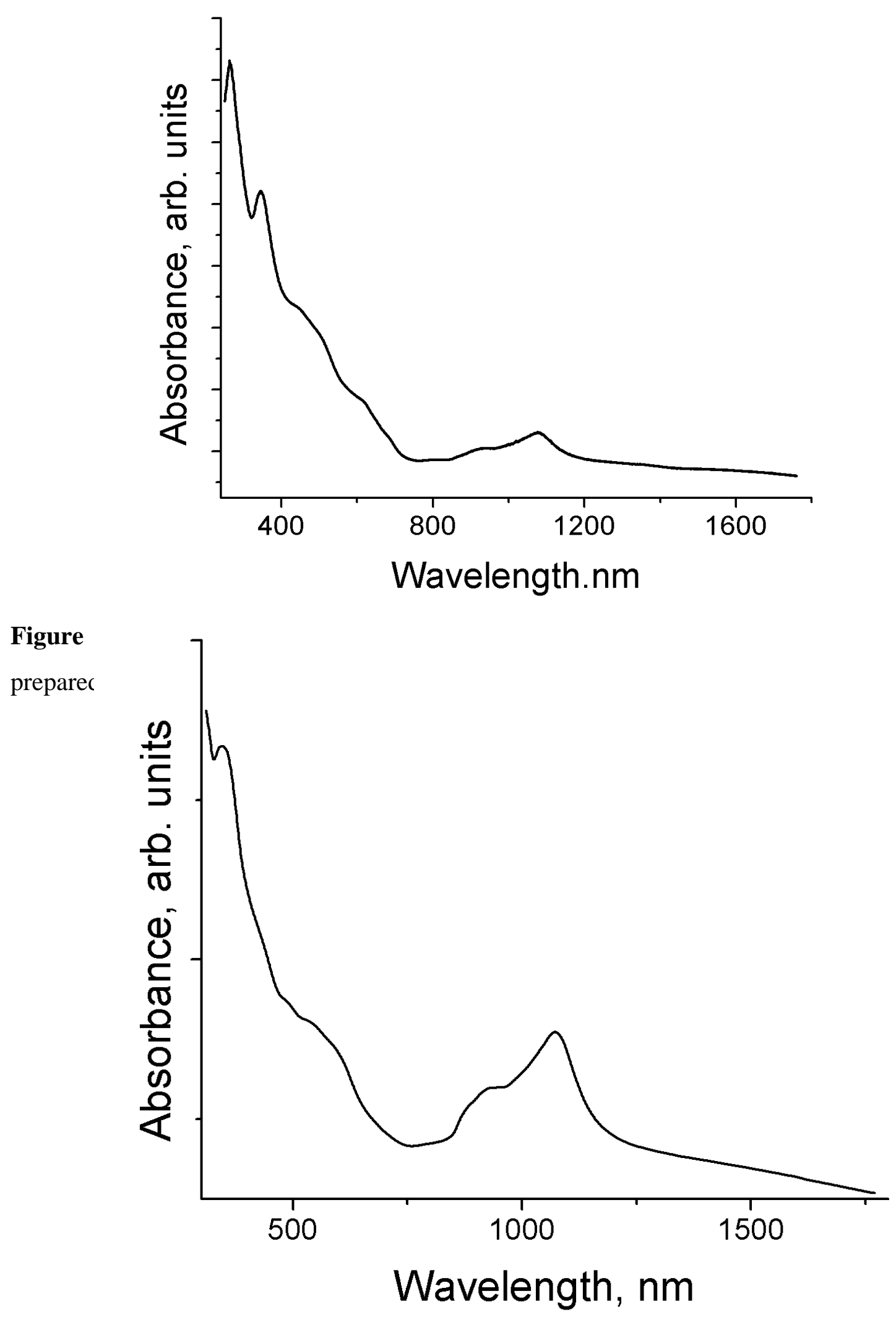

pellet

Figure S6. UV-visible-NIR spectrum of $\left\{\text { cryptand }[2,2,2]\left(\mathrm{Na}^{+}\right)\right\}_{2}\left(\mathrm{C}_{60}{ }^{-}\right)_{2} \cdot \mathrm{C}_{6} \mathrm{H}_{4} \mathrm{Cl}_{2} \cdot \mathrm{C}_{6} \mathrm{H}_{14}$ (4) in 
